\title{
Influence of Solar Heating on the Performance of Integrated Solar Cell Microstrip Patch Antennas
}

\author{
Maria Roo Ons \\ Technological University Dublin, kmariajose@yahoo.es \\ S. Shynu \\ Technological University Dublin, sshynu@tudublin.ie \\ M Seredynski \\ Warsaw University of Technology
}

See next page for additional authors

Follow this and additional works at: https://arrow.tudublin.ie/ahfrcart

Part of the Electromagnetics and Photonics Commons, and the Systems and Communications Commons

\section{Recommended Citation}

Roo-Ons, M.J. (2009) et al. Influence of Solar Heating on the Performance of Integrated Solar Cell Microstrip Patch Antennas. Solar Energy, 84, (9), pp.1619-1627. doi:10.1016/j.solener.2010.06.007

This Article is brought to you for free and open access by the Antenna \& High Frequency Research Centre at ARROW@TU Dublin. It has been accepted for inclusion in Articles by an authorized administrator of ARROW@TU

Dublin. For more information, please contact

arrow.admin@tudublin.ie, aisling.coyne@tudublin.ie, gerard.connolly@tudublin.ie.

Funder: Science Foundation Ireland

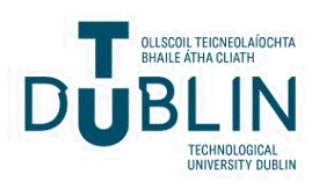


Authors

Maria Roo Ons, S. Shynu, M Seredynski, Max Ammann, Sarah McCormack, and Brian Norton

This article is available at ARROW@TU Dublin: https://arrow.tudublin.ie/ahfrcart/19 
Influence of solar heating on the performance of integrated solar cell microstrip patch antennas

\author{
M. J. Roo-Ons ${ }^{*(1)}$, S.V. Shynu ${ }^{(1)}$, M. Seredynski( ${ }^{(2)}$, M.J. Ammann ${ }^{(1)}$, S. J. McCormack ${ }^{(3)}$, B. Norton ${ }^{(3)}$, \\ (1) Antenna \& High Frequency Research, School of Electronic and Communications Engineering, \\ Dublin Institute of Technology, Ireland \\ ${ }^{(2)}$ Institute of Heat Engineering, Warsaw University of Technology, Poland \\ ${ }^{(3)}$ Dublin Energy Lab., Focas Institute, Dublin Institute of Technology, Ireland
}

\begin{abstract}
The integration of microstrip patch antennas with photovoltaics has been proposed for applications in autonomous communication systems for building façades. Full integration was achieved using polycrystalline silicon solar cells as both antenna ground plane and direct current power generation in the same device. This paper provides an overview of the proposed photovoltaic antenna designs and characterises the variation of the electromagnetic properties of the device with temperature and solar radiation. Measurements for both copper and solar antennas are reported on three different commercial laminates with contrasting values for thermal coefficient of the dielectric constant.
\end{abstract}

Keywords: PV antenna; Microstrip patch; Photovoltaic cell; Temperature; Thermal coefficient of dielectric constant.

Nomenclature

$C_{\mathrm{m}} \quad$ specific heat capacity of material $\left(\mathrm{J} \mathrm{kg}^{-1} \mathrm{~K}^{-1}\right)$

$c_{o} \quad$ speed of light in free space $\left(3 \times 10^{8} \mathrm{~m} \mathrm{~s}^{-1}\right)$

$d_{\mathrm{m}} \quad$ depth or thickness of material in module (m)

$f_{o} \quad$ fundamental resonant frequency $(\mathrm{Hz})$

$h_{\mathrm{c}} \quad$ convection heat transfer coefficient $\left(\mathrm{W} \mathrm{m}^{-2} \mathrm{~K}^{-1}\right)$

\footnotetext{
* Corresponding author. Tel: +353 1 4024716; Fax: +35314024690,

E-mail address: mariajose.rooons@student.dit.ie (M.J. Roo-Ons).
} 


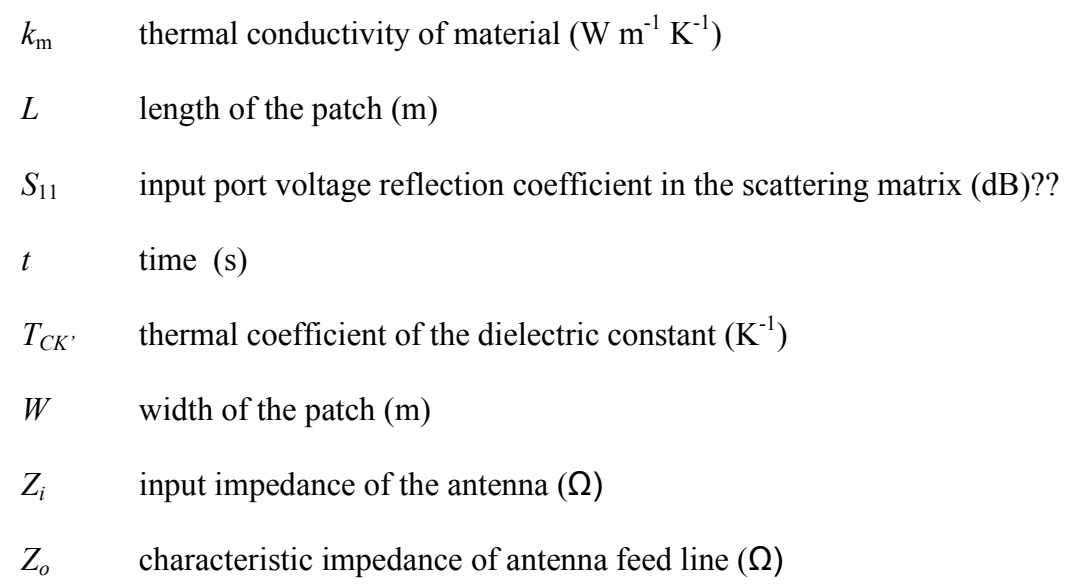

1. Introduction

Urban mobile cellular communications use an increasingly large number of limited-range building-mounted antennas operating at low power. The installation of microcell antennas on buildings often requires expensive and time-consuming retrofitting of electrical supply cables, which can lead to concern over visual amenity, vandalism and maintenance. Photovoltaic (PV) powered microcell transceivers with integrated batteries offer a high inherent reliability and are unsusceptible to grid-supply interruptions. Vertical façade PV panels for building integration are designed usually with a flat external profile (Zacharopoulos et al., 2000; Mondol et al., 2005) which allows integration with planar antennas. The integration of polycrystalline silicon (poly-Si) solar cells with planar microstrip antennas in building façade with appropriate solar exposure for applications in autonomous communications systems reduces the marginal cost of use of solar energy, thereby improving its 
economic viability due to (i) the dual-function integration nature of the application and (ii) the elimination of the capital cost of cables and the recurrent cost of grid-supplied electricity.

Microstrip patch antennas (MPA) have been used extensively for both the simplest and most demanding microwave applications; they are inexpensive to manufacture, conformable, lightweight and mechanically rugged. Their behaviour is relatively simple to predict (Garg et al., 2001; Herscovici, 2008). A rectangular MPA, as illustrated in Fig. 1 consists of a very thin square shaped metallic radiating patch on one side of a dielectric substrate, with a continuous metal layer bonded to the opposite side acting as ground plane for the radiofrequency (RF) signal. MPA are planar structures manufactured usually on common circuit board laminates (Harper, 2003). The particular MPA discussed in this paper is fed by an inset microstrip line connected to a coaxial connector at the edge of the structure, as shown in Fig.1.

Early interest in combining antennas with PV panels was in satellite communications, where antennas and solar cells compete for the same scarce surface area. The first technique used was to place solar cells directly onto microstrip patch antennas, avoiding the effective fringing electric fields region (Tanaka et al., 1996). It was found that although the area immediately surrounding the antenna patch should be avoided, solar cells could be co-located with the antenna patch itself and the dielectric substrate. In an innovative approach, standard Si solar cells were used underneath a metallodielectric reflect-array of printed crossed-dipoles for a horn-reflector antenna (Zawadzki et al., 2003). As thin amorphous silicon (a-Si) technology on polymer substrates developed, an increased level of integration was achieved with the possibility of cutting the cells to fit into complex geometries like slot antennas (Vaccaro et al., 2003). Other attempts to integrate solar cells with antennas have studied the feasibility of using the conductive contacts of monocrystalline silicon (mono-Si) solar cells as the radiating elements for a GPS (Global Positioning System) and GSM (Global System for Mobile) vehicular antenna (Henze et al., 2004).

The feasibility of using poly-Si solar cells as the ground plane for inset-fed microstrip square patch antennas has been examined on a single $156 \mathrm{~mm}$ x $156 \mathrm{~mm}$ cell (Shynu et al., 2009) under ambient room light intensity and temperature $\left(293 \mathrm{~K}, 1.4 \mathrm{~W} \mathrm{~m}^{-2}\right)$. Experimental results suggested it was viable to use a poly-Si ground for a microstrip patch (PV antenna) as illustrated in Fig.2, when compared with the conventional square patch antenna with copper ground plane shown in Fig.3. The microwave substrate covers an area of only $5.5 \%$ of the solar cell area and the measured solar cell 
efficiency with the antenna integrated was found to be $12.3 \%$. This novel low cost method of integration does not require laser cutting or complex RF-DC decoupling arrangements in the feed.

Antennas incorporated into building façades (Norton et al, 2008) will experience diurnal temperature variations. It is necessary to determine how antenna properties change as its substrate materials undergo thermal expansion with temperature. The dielectric constant can be sensitive to temperature and thus shift the frequency of operation.

The aim of this paper is to characterise the change in performance of PV antennas when subjected to temperature changes due to solar radiation. The study compares experimental device performance for microstrip patch antennas printed on three commercial laminates with different thermal coefficients of the dielectric constant, for both the solar prototypes and conventional antennas with copper ground plane.

2. Characterization of the manufactured copper prototypes and dielectric substrates

MPAs were fabricated on double-sided copper-clad laminates, with 35 micron electrodeposited copper on a dielectric resin substrate. A 34 x $34 \mathrm{~mm}$ square-shaped patch and a microstrip feed line were etched on one side of the laminates using a LPKF ProtoMat C60 circuit plotter and milling robot.

An antenna's resonant frequency depends not only on its physical dimensions but also on the electrical properties of the dielectric material. The three laminates under test were Ro4003 (Rogers Corporation), RF45 (Taconic Advance Dielectric Division), and FR4 (LPKF Laser and Electronics AG). The main laminate parameters are:

- $\varepsilon_{r}$, the dielectric constant of the substrate. In microstrip antennas the preferred dielectric constant values range from 1 to 5; smaller values improve radiation efficiency and bandwidth, but higher values are chosen when miniaturization is required (Hoorfar et al., 2001).

- $\tan \delta$, the dielectric loss tangent; a measure of the loss-rate of power inside the dielectric material. It is directly proportional to the frequency of operation. A high loss tangent reduces antenna gain and efficiency although it may increase the bandwidth. 
- $T_{C K}$, the thermal coefficient of the dielectric constant. It is a measure of how the dielectric constant is affected by changes in temperature. Its units are $\mathrm{K}^{-1}$, positive when $\varepsilon_{r}$ increases with temperature.

Based on a cavity model approximation (Garg et al., 2001), the fundamental resonant frequency of the rectangular patch with a thin substrate as presented in Fig. 1 is inversely proportional to the patch length $(L)$ and to the square-root of dielectric constant $\left(\varepsilon_{r}\right)$ of the substrate, with an approximated value given by Eq. (1)

$$
f_{o=} \frac{c_{o}}{2 L \sqrt{\varepsilon_{r}}}
$$

where $c_{\mathrm{o}}$ is the speed of light in free space. Analyses are available that introduce the effects of the substrate height $\left(d_{s u b}\right)$, the patch width $(W)$, and the copper thickness $\left(d_{c u}\right)$ (Garg et al., 2001). Changes in the dielectric constant of the laminate affect the resonant frequency of the patch antenna as given by Eq. (1). This may limit the use of the device within a limited temperature range, and is especially critical in outdoor applications. The laminate characteristics are presented in Table 1. Laminates with an absolute value of $T_{C K},<6010^{-6} \mathrm{~K}^{-1}$ are considered to be stable with temperature.

- $d_{s u b}$, the height of the substrate, as illustrated in Fig. 1. A thicker substrate will increase the radiation efficiency, and improve the impedance bandwidth, but also presents a greater risk of surface wave excitation.

- $d_{c u}$, the thickness of the copper cladding deposited on the substrate of the laminate as depicted in Fig.1; typical values are $0.035 \mathrm{~mm}$ or $0.017 \mathrm{~mm}$.

\section{Fundamentals of microstrip antennas}

Microstrip antennas are inherently narrowband, with typical bandwidths in the range of 1-4\% of the centre frequency, though it can be increased (Pozar, 1995; Herscovici, 2008). These antennas are in general half-wavelength structures operated at their fundamental or first resonant mode $\mathrm{TM}_{10}$ as given by Eq. (1). 
The "polarization" of an antenna refers to the polarization of the wave it radiates/receives. It describes the orientation of the electric-field vector oscillation when observed in the plane perpendicular to the wave's direction of travel. Circular or elliptical polarizations are possible for patch antennas (Balanis, 1997) but for simplicity the proposed antenna polarization is linear. Although any continuous shape is possible for the patch, the simple rectangular geometry is used most widely.

\subsection{Feeding technique}

A coaxial cable with characteristic impedance $\left(Z_{o}\right)$ of $50 \Omega$ (Pozar, 1998) is the most widespread transmission line used to feed an antenna. Many different configurations can be used to connect the feed to the microstrip patch (Zürcher et al., 1995). An inset microstrip line was chosen to feed the antenna in order to avoid piercing the cell; furthermore it can be printed on the same laminate and offers flexibility in impedance matching by controlling the inset position. In this work, the dimensions of patch and the inset feed were optimized using the time-domain solver of the integralequation based electromagnetic simulator CST Microwave Studio (CST, 2009).

\subsection{Impedance matching, microwave reflection coefficient and operational frequency band}

Efficient radiation/reception requires an antenna to have the correct dimensions to resonate at the incoming signal's frequency and to provide a good impedance match. An antenna is connected to a transmitter or to a receiver using a coaxial cable or a microstrip transmission line.

The antenna input impedance $\left(Z_{i}\right)$ can be defined as the ratio between the RF voltage and current at the antenna terminal and it is frequency dependent. In order for maximum power transfer between transmission line and antenna, the characteristic impedance of the transmission line $\left(\mathrm{Z}_{\mathrm{o}}\right)$ must equal the antenna input impedance, otherwise a fraction of the signal will be reflected.

The reflection coefficient $(\Gamma)$ (Balanis, 1997) is given by,

$\Gamma=\frac{Z_{o}-Z_{i}}{Z_{o}+Z_{i}} \quad 0 \leq|\Gamma| \leq 1$ 
A perfect impedance match is achieved by $\Gamma=0$, when $Z_{i}=Z_{o}$. In this case, the power transmission between the antenna and the line is maximum. The worst impedance match is given by $\Gamma$ $=-1$ or 1 , corresponding to a short or an open circuit as the load impedance. At microwave frequencies, the reflection coefficient is commonly expressed in $\mathrm{dB}$ and known as the " $S_{11}[\mathrm{~dB}]$ " as in Eq. (3),

$S_{11}[\mathrm{~dB}]=-20 \log (|\Gamma|)$

$$
-\infty \leq S_{11}[\mathrm{~dB}] \leq 0
$$

For an antenna to be matched sufficiently to its input transmission line, $S_{11}[\mathrm{~dB}]<-10 \mathrm{~dB}$, i.e., $|\Gamma|<0.3163$, must be fulfilled. Then less than $10 \%$ of the incident signal is reflected. The range of frequencies for which this occurs is known as the impedance bandwidth.

\subsection{Radiation pattern and gain}

The antenna radiation pattern is a graphical representation of the relative strength of radiated power in the far field sphere surrounding the antenna, as a function of space coordinates (Balanis, 1997). Fig. 4 shows the typical three dimensional (3D) radiation patterns in spherical coordinates for a half-wave rectangular patch excited in its fundamental mode. It can be observed that, directivity is maximum along the $\mathrm{z}$-axis ( theta $=0^{\circ}$ ) and minimum behind the groundplane. The antenna gain refers to the directive gain of the antenna in the direction of maximum radiation. This value varies in the region of 3-7 $\mathrm{dBi}$ for a single patch, depending on the geometry and losses of the structure, specifically the dielectric losses of the substrate $(\tan \delta)$. Although such variations can be observed in Table 2, measurements show the shape of the PV antenna radiation pattern is essentially the same as that of ideal patch antenna.

\section{PV antenna design}

Three PV antennas were fabricated by removing the rearside copper cladding and attaching the solar cell to act as a ground plane as shown in Figs. 2 and 3. It can be observed from Fig. 2a that the spare substrate around the radiating patch was eliminated to reduce shade over the cell. An 
additional dielectric layer of FR4 material is placed beneath the solar ground plane to provide mechanical support due to the brittle nature of the solar cell (Fig. 2b). The cross-sectional view of both conventional antenna and PV antenna structures can be compared in Fig. 5.

Poly-Si solar cells of dimensions $156 \mathrm{~mm}$ x $156 \mathrm{~mm}$ x $0.25 \mathrm{~mm}$ (Solland Solar Holding BV) were used for the integration. Their rear-side is covered with a thin homogeneous aluminium layer of $36 \mu \mathrm{m}$ in thickness, while the front contacts consist of 57 thin silver parallel lines for DC collection (17 $\mu \mathrm{m}$ in thickness, $0.1 \mathrm{~mm}$ width) crossed by two $2 \mathrm{~mm}$ major bus bars. In between an $\mathrm{n}^{+}-\mathrm{p}-\mathrm{p}^{+}$doped silicon layer of thickness $210 \mu \mathrm{m}$ is responsible for the inherent electrical potential in the cell when illuminated.

Previous investigations have shown that antenna gain depends on the orientation of the front contacts of the solar cell with respect to the patch (Shynu et al., 2009); the front contacts could be either oriented in parallel as shown in Fig. 2a or rotated $90^{\circ}$ and so oriented in perpendicular with the polarization of the radiated electric field. In the case of the copper ground plane, no other conductors were present in the cavity formed between the microstrip patch and the ground plane. When this was replaced by the poly-Si solar cell, the DC conductive components provided a good ground plane for the patch. Analysis of the currents in the cavity formed between the patch and the rearside explained the dependence of the solar antenna parameters on the orientation of the grid (Roo Ons et al., 2008). It was seen that when the front contacts are aligned in parallel to the resultant electric field, they acted as a partial reflecting structure for the microwaves, therefore mitigating the penetration of energy into the silicon and the associated losses. The antenna performance showed some degradation, in comparison to the microstrip patch with copper ground plane. However when the thin front contacts were oriented perpendicular to the patch electric field, more of the field penetrated into the lossy silicon layer towards the aluminium layer of the cell, resulting in a further degradation of the solar antenna gain performance.

In the analysis of the performance of the PV antennas with temperature variation due to solar radiation only the parallel orientation of the front contacts with respect to the radiated field as presented in Fig. 2 has been considered, because it provides the best gain performance.. 
5. Effect of solar radiation intensity variation on microwave reflection coefficient. Measurement procedure and results.

The sensitivity of the PV antenna resonant frequency to change in temperature induced by solar radiation was measured and compared with the behaviour of the conventional patch antenna on the same laminate and under the same solar radiation conditions. The measurement on each of the proposed AUT (Antenna under Test) took place in a closed chamber with no forced ventilation (estimated convection coefficient $h_{c}=5.25 \mathrm{~W} \mathrm{~m}^{-2} \mathrm{~K}^{-1}$ ) and an ambient temperature of $293 \mathrm{~K}$.

Incident insolation was first measured at the centre of the irradiated area using a Kipp \& Zonen CM11 pyranometer in the AUT position shown in Fig. 6. A Griven INSE 1200 MSR metal halide lamp continuous solar simulator was adjusted to achieve insolation of $1000 \mathrm{~W} \mathrm{~m}^{-2}$. The pyranometer was then removed and substituted by the AUT connected to a ZVB 8 Rohde \& Schwarz Vector Network Analyzer, which was used to measure $S_{11}$ (i.e., microwave reflection coefficient as defined in Eq. (3)) over a 30 minute insolation period. Fig. 7 shows the variation of the antenna operational bandwidth in form of microwave reflection coefficient $\left(S_{11}\right)$ for both copper and PV based antennas. Results are presented for the patch on FR4, RF45 and Ro4003 dielectric substrates.

The measured results are summarized in Table 2 where $f_{o}(\mathrm{GHz})$ denotes the original resonant frequency of the evaluated device just before illumination (time $=0 \mathrm{~min}$ in Fig.7). The reduction in resonant frequency seen when the copper groundplane was replaced by the poly-Si groundplane was caused by an increase in effective dielectric constant for the patch. Although there was a shift in the resonant frequency with change in illumination, as shown in Fig. 7 and Table 2, the bandwidth (BW) remained stable.

The gain values presented in Table 2 were measured through standard RF antenna measurement procedures (Balanis, 1997) in an anechoic chamber. The slight drop in gain and increase in bandwidth observed when the solar cell replaced the copper ground plane can be attributed to the increase losses of this inhomogeneous ground plane (hybrid combination of silver front contacts, silicon and aluminium layer). The change in resonant frequency with temperature during 30 minutes continuous exposure to $1000 \mathrm{~W} \mathrm{~m}^{-2}$ insolation is also displayed in Table 2. This difference is presented both as an absolute value in $\mathrm{MHz}$ and also as a percentage of the original $f_{o}$. In a laminate 
with a positive $T_{C K}$, the substrate's $\varepsilon_{r}$ will increase with temperature and the resonant frequency decreases.

The variations observed in $S_{11}$ for both copper and PV based antennas (Table 2 and Fig. 7) are dependent on the thermal stability of the dielectric substrate used and were reversible when the solar simulator was switched off. The microstrip patch antenna fabricated on the Ro4003 laminate $\left(T_{C K}{ }^{\prime}=\right.$ $+1710^{-6} \mathrm{~K}^{-1}$ ) showed no change in its operational bandwidth with 30 minutes $1000 \mathrm{~W} \mathrm{~m}^{-2}$ insolation exposure for both copper and PV ground planes. The change observed with 30 minutes $1000 \mathrm{~W} \mathrm{~m}^{-2}$ insolation exposure for the RF45 prototypes $\left(T_{C K}, \approx-13510^{-6} \mathrm{~K}^{-1}\right)$ was $2 \mathrm{MHz}$ for the copper prototype and $4 \mathrm{MHz}$ for the PV antenna. The largest change was observed with the FR4 prototypes $\left(T_{C K}, \approx+60010^{-6} \mathrm{~K}^{-1}\right)$; up to $12 \mathrm{MHz}$ for the ideal antenna, and a maximum of $13 \mathrm{MHz}$ for the PV antenna.

The temperatures reached by the antennas during the continuous 30 minutes exposure to 1000 $\mathrm{W} \mathrm{m} \mathrm{m}^{-2}$ insolation was also measured for the front of the patch and the back of the devices with T-type Copper-Constantan thermocouples, at the points F and B shown in Figs. 2 and 3. Measured results were compared with simulations using FLUENT (ANSYS FLUENT Flow Modelling Software, 2009) for the material properties presented in Table 3. Fig. 8 shows the FR4 based antenna's temperature variation during 30 minutes exposure to $1000 \mathrm{~W} \mathrm{~m}$ insolation. Good agreement between measurement and simulation was achieved in general. However, only reasonable agreement was achieved for the rear side of the PV antenna, due to the presence of small air gaps present in the bonding of the solar cell to the mechanical rear support.

The measured temperature for the front of the radiating patch in the copper antenna as shown in Fig. 8(a), reaches $327.55 \mathrm{~K}$, whereas the patch in the PV antenna (Fig. 8(b)) reaches 330.83K due to the presence of the solar cell. The difference between the front and back temperatures is larger for the PV antenna due to the extra layer of FR4 support shown in Fig. 5(b). The measured difference is 2.39 $\mathrm{K}$ for the copper antenna and $6.16 \mathrm{~K}$ for the PV antenna. Figure 8 also shows the simulated temperature trend at the FR4-PV boundary for the PV antenna. A temperature of $329.01 \mathrm{~K}$ was achieved at this internal boundary after the 30 minutes of $1000 \mathrm{~W} \mathrm{~m}^{-2}$ insolation.

6. Conclusions 
The feasibility of using poly-Si solar cells as ground plane for common inset-fed microstrip square patch antennas is demonstrated. The performance of the PV antenna was similar to the ideal conventional antenna with a copper ground plane but with a slight decrease in gain and increase in bandwidth. Because the microstrip is low-profile, it provides a promising and low-cost method of integration of PV and antennas for applications in autonomous communications systems in building façades.

The performance of the proposed structure with 30 minutes exposure to incident radiation of $1000 \mathrm{Wm}^{-2}$ is presented for three commercial laminates (Ro4003, FR45 and FR4) with different thermal coefficients of the dielectric constant was undertaken.

The radiating patch in the PV antenna was found to reach slightly higher temperatures due to the presence of the solar cell than would a conventional microstrip patch antenna with copper ground plane. However, the solar antenna resonant frequency showed similar sensitivity to temperature variation as the corresponding copper prototypes. This shows that the performance of a microstrip patch under temperature stress is dependent mainly on the thermal stability of the dielectric substrate. The PV ground plane in the proposed structure therefore does not degrade significantly the antenna performance compared to a conventional antenna.

In order to avoid changes in the operational frequency and consequential performance degradation, temperature stable laminates (abs $\left[T_{C K^{\prime}}\right]<6010^{-6} \mathrm{~K}^{-1}$ ) should be employed in solar antennas for façade applications.

\section{Acknowledgments}

The authors acknowledge the support of Science Foundation Ireland (SFI) who fund this project through the Research Frontiers Program. We also would like to thank Dr. Marek Rebow and Dr. Mick McKeever for valuable contribution to this work. 
References

ANSYS FLUENT Flow Modelling Software, 2009. FLUENT information available at $<$ www.fluent.com $>$

Balanis, C. A., 1997. Antenna Theory: Analysis and Design, Second Ed. John Wiley \& Sons, New York, pp. 28-115 and 859-872.

CST Computer Simulation Technology, 2009. CST Microwave Studio information available at <www.cst.com/Content/Products/MWS/Overview.aspx $>$

Davis, M.W., Fanney, A.H., Dougherty, B.P., 2003. Measured versus predicted performance of building integrated photovoltaics. ASME Journal of Solar Energy Engineering, 125,1, pp. 21-27.

Domeij Bäckryd, R., 2005. Simulation of heat transfer on Gas Sensor Component. Student Theses from Linköping University, available at $<$ www.ep.liu.se/undergraduate/abstract.xsql?dbid=131>

Garg, R., Bhartia, P., Bahl, I., Ittipiboon, A., 2001. Microstrip Antenna Design Handbook, Artech House, Norwood, MA, pp. 253-316.

Harper, C.A., 2003. Electronic Materials and Processes Handbook, Third Ed. Mc Graw-Hill Handbooks, New York, Chapter 7.

Henze, N., Weitz, M., Hoffmann, P., Bendel, C., Kirchhof, J., Früchtig, H., 2004. Investigation on Planar antennas with Photovoltaic Solar Cells for Mobile Communications. IEEE International Symposium on Personal, Indoor and Mobile Radio Communication (PIMRC), vol.1, pp. 622-626.

Herscovici, N., 2008. New considerations in the design of microstrip antennas. IEEE Transactions on Antennas and Propagation, vol. 46, No 6, pp. 807-812.

Hoorfar, A., Perrotta, A., 2001. An Experimental Study of Microstrip Antennas on Very High Permittivity Ceramic Substrates and Very Small Ground Planes. IEEE Trans. Antennas Propagat., vol. 49, No 5, pp. 838-840.

Jones, A.D., Underwood, C.P., 2001. A thermal model for photovoltaic systems. Solar Energy, 70, 4, pp. 349-359.

LPKF Laser and Electronics AG, Garbsen, Germany. FR4 laminate information available at <www.lpkf.com/_mediafiles/1026-product-catalog.pdf> 
Mondol, J.D., Yohanis, Y.G., Smyth, M., Norton, B., 2005. Long-term Validated Simulation of a Building Integrated Photovoltaic System. Solar Energy, 78, pp. 163-176.

Norton, B., Eames, P.C., Mallick, T.C, Huang, M.J., McCormack, S.J., Mondol, J., Yohanis, Y.G., 2008. Enhancing the performance of building integrated photovoltaics. In: Goswami, D.Y. (Ed.), Advances in Solar Energy - An Annual Review of Research and Development in Renewable Energy Technologies, Elsevier.

Pozar, D. M., 1995. A Review of Bandwidth Enhancement Techniques for Microstrip Antennas. In: Pozar, D.M., Schaubert, D.H. (Eds.), Microstrip Antennas, The Analysis and Design of Microstrip Antennas and Arrays, IEEE Press, New York, pp. 157-166.

Pozar, D.M., 1998. Microwave Engineering, third ed. John Wiley \& Sons, Inc., New York, pp. 91-160.

Rogers Corporation, Advanced Circuit Materials, 100. S. Rooswelt Avenue Chandler, AZ 85226, USA. Ro4003 laminate information available at < www.rogerscorp.com/documents/726/acm/RO4000-Laminates-data-sheet-and-fabrication-guidelinesRO4003C-RO4350B.aspx>

Roo Ons, M.J., Shynu, S.V., Ammann, M.J., McCormack, S.J., Norton, B., 2008. On Surface Currents in a Polycrystalline silicon solar Cell Acting as Ground Plane for Microstrip Patch Antennas. In: Proceedings of IEEE AP-S International Symposium on Antennas and Propagation, San Diego (USA), July 5-10, pp. Session 431, Paper 4.

Shynu, S.V., Roo Ons, M.J., McEvoy, P., Ammann, M.J., McCormack, S.J., Norton, B., 2009. Integration of Microstrip Patch Antenna with Polycrystalline Silicon Solar Cell. IEEE Transactions on Antennas and Propagation, 2009, (in press).

Solland Solar Holding BV, The Netherlands. S156PS 375 solar cell information available at <www.sollandsolar.com/IManager/Content/4680/qf17/mt1537/mi30993/mu1200672000/mv2341>

Taconic Advance Dielectric Division, Petersburgh, NY (USA). RF45 laminate information available at $<$ www.taconic-add.com/pdf/taconic-laminate_material_guide.pdf $>$

Tanaka, M., Suzuki, Y., Araki, K., Suzuki, R., 1996. Microstrip Antennas with Solar Cells for Microsatellites. Electronics Letters, 31, 1, pp. 5-6. 
Vaccaro, P., Mosig, de Maagt, 2003. Two Advanced Solar Antenna “SOLANT” Designs for Satellite and Terrestrial Communications. IEEE Trans. Antennas Propagat., vol. SP-51, No 8, pp. 2028-2034.

Zacharopoulos, A., Eames, P.C., McLarnon, D., Norton, B., 2000. Linear Dielectric NonImaging Concentrating Covers for PV Integrated Building Facades. Solar Energy, 68, 5, pp. 439-452. Zürcher, J.-F., Gardiol, F.E., 1995. Broadband Patch Antennas, Artech House, Noorwood, MA, pp. 27-31. 
Figure captions

Fig. 1. Square microstrip patch antenna fed by an inset microstrip line.

Fig. 2. Antenna with poly-Si solar cell as ground plane: (a) front and (b) back view. F and B denote the positions of thermocouples at the front and back of the structure respectively.

Fig. 3. Conventional microstrip patch antenna with copper ground plane: (a) front and (b) back view. $\mathrm{F}$ and $\mathrm{B}$ denote the positions of thermocouples at the front and back of the structure respectively.

Fig. 4. Typical simulated 3D microwave radiation pattern of a square microstrip patch antenna: (a) front view of the radiation lobe with maximum directivity for theta $=0^{\circ}$ and (b) back view of the radiation lobe with directivity gain $<0 \mathrm{dBi}$.

Fig. 5. Cross-sectional view of the antenna structures for both (a) standard microstrip patch antenna with copper ground plane and (b) PV antenna with poly-Si solar cell as ground plane.

Fig. 6. Illumination of the PV antenna with a Griven INSE 1200 MSR metal halide lamp.

Fig. 7. Variation of measured antenna $S 11$ with 30 minutes exposure to $1000 \mathrm{~W} \mathrm{~m}^{-2}$ simulated insolation, for both copper and PV antennas. Results presented for the laminates FR4, RF45 and Ro4003.

Fig. 8. Temperature variation for the FR4 based prototypes for 30 minutes exposure to $1000 \mathrm{~W} \mathrm{~m} \mathrm{~m}^{-2}$ simulated insolation, for (a) copper and (b) PV antenna. 
Table 1.

Description of the three laminates characterised in terms of the substrate composition, dielectric constant $\left(\varepsilon_{r}\right)$, loss tangent ( $\left.\tan \delta\right)$, thermal coefficient of the dielectric constant $\left(T_{C K^{\prime}}\right)$, height of the substrate $\left(d_{\text {sus }}\right)$, and thickness of the copper layer $\left(d_{c u}\right)$.

\begin{tabular}{lllllll}
\hline Laminate & $\begin{array}{l}\text { Substrate's } \\
\text { composite }\end{array}$ & $\varepsilon_{\mathrm{r}}$ & $\tan \delta\left[\mathrm{Npm}^{-1}\right]$ & $T_{C K^{\prime}}\left[\mathrm{K}^{-1}\right]$ & $d_{\text {sus }}[\mathrm{m}]$ & $d_{c u}[\mathrm{~m}]$ \\
\hline FR4 & $\begin{array}{l}\text { Epoxy-glass } \\
\text { resin }\end{array}$ & 4.2 & 0.0200 & $+60010^{-6}$ & $1.6010^{-3}$ & $0.03510^{-3}$ \\
RF45 & $\begin{array}{l}\text { Ceramic } \\
\text { Ro4003 }\end{array}$ & 4.5 & 0.0013 & $-13510^{-6}$ & $1.5710^{-3}$ & $0.03510^{-3}$ \\
& $\begin{array}{l}\text { woven glass } \\
\text { Ceramic } \\
\text { filled PTFE }\end{array}$ & 4.3 & 0.0037 & $+1710^{-6}$ & $1.5210^{-3}$ & $0.03510^{-3}$ \\
\hline
\end{tabular}


Table 2.

Comparative antenna parameter values and changes in resonant frequencies with temperature after 30 minutes exposure to insolation $1000 \mathrm{~W} \mathrm{~m}^{-2}$, for the laminates FR4, RF45 and Ro4003.

\begin{tabular}{|c|c|c|c|c|c|c|c|c|}
\hline & & \multirow[t]{2}{*}{ Antenna type } & \multirow[t]{2}{*}{$f_{o}[\mathrm{GHz}]$} & \multicolumn{2}{|l|}{ BW } & \multirow[t]{2}{*}{ Gain [dBi] } & \multicolumn{2}{|c|}{ Change in $f o$} \\
\hline & & & & [MHz] & $\%$ & & [MHz] & $\%$ \\
\hline \multirow{6}{*}{ Laminate } & FR4 & copper & 2.28 & 59 & 2.5 & 3.10 & -12 & 0.52 \\
\hline & & PV & 2.22 & 90 & 4.0 & 1.86 & -13 & 0.58 \\
\hline & RF45 & copper & 2.28 & 26 & 1.1 & 5.24 & +2 & 0.08 \\
\hline & & PV & 2.21 & 34 & 1.5 & 4.82 & +4 & 0.18 \\
\hline & Ro4003 & copper & 2.53 & 30 & 1.2 & 5.96 & 0 & 0.00 \\
\hline & & PV & 2.43 & 49 & 2.0 & 4.95 & 0 & 0.00 \\
\hline
\end{tabular}


Table 3.

Density $\left(\rho_{\mathrm{m}}\right)$, specific heat capacity $\left(C_{\mathrm{m}}\right)$, thermal conductivity $\left(k_{\mathrm{m}}\right)$, solar absorptance $\left(\alpha_{\mathrm{m}}\right)$ and depth $\left(d_{\mathrm{m}}\right)$ of materials used.

\begin{tabular}{|c|c|c|c|c|c|c|}
\hline & & $\rho_{\mathrm{m}}\left[\mathrm{kg} \mathrm{m}^{-3}\right]$ & $C_{\mathrm{m}}\left[\mathrm{J} \mathrm{kg}^{-1} \mathrm{~K}^{-1}\right]$ & $k_{\mathrm{m}}\left[\mathrm{W} \mathrm{m} \mathrm{m}^{-1} \mathrm{~K}^{-1}\right]$ & $\alpha_{\mathrm{m}}$ & $d_{\mathrm{m}}[\mathrm{m}]$ \\
\hline \multirow[t]{3}{*}{ Material } & Copper & 8939 [3] & 393 & $390.00^{[3]}$ & $0.50^{[5]}$ & $0.03510^{-3}[4]$ \\
\hline & FR4 & $1900^{[3]}$ & $840^{[5]}$ & $0.23^{[3]}$ & $0.65^{[5]}$ & $1.60010^{-3[4]}$ \\
\hline & $\begin{array}{l}\text { Poly-Si } \\
\text { solar cell }\end{array}$ & $2330^{[1]}$ & $712^{[1]}$ & $148.00^{[1]}$ & $0.70^{[2]}$ & $0.25910^{-3}[6]$ \\
\hline
\end{tabular}

*Sources: ${ }^{[1]}$ Davis et al., 2003; ${ }^{[2]}$ Jones et al., 2001; ${ }^{[3]}$ Domeij Bäckryd, R., 2005; ${ }^{[4]}$ LPKF Laser and Electronics AG; ${ }^{[5]}$ empirical estimation; ${ }^{[6]}$ in-lab measurement. 
Fig. 1.

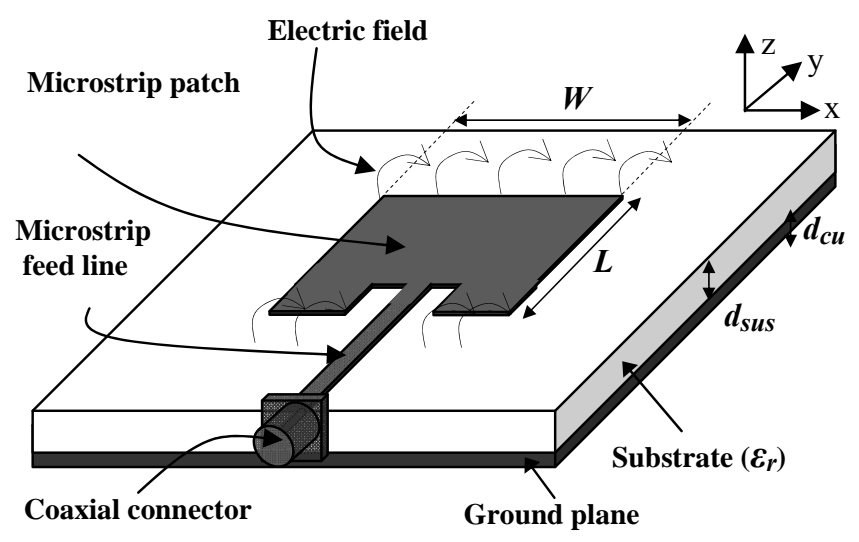

Fig. 2

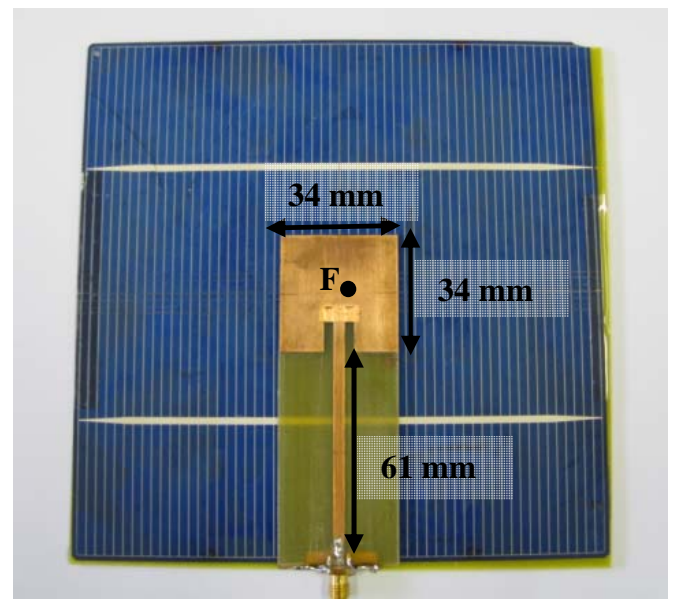

(a)

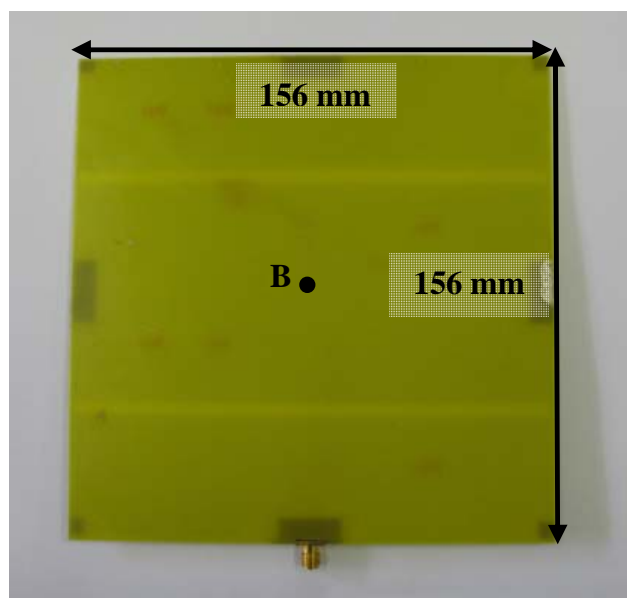

(b) 
Fig. 3.

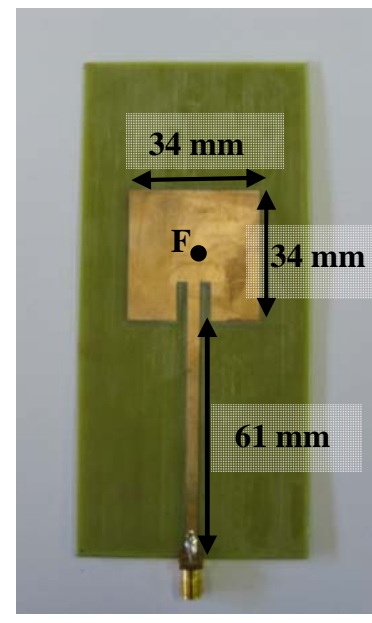

(a)

Fig. 4.

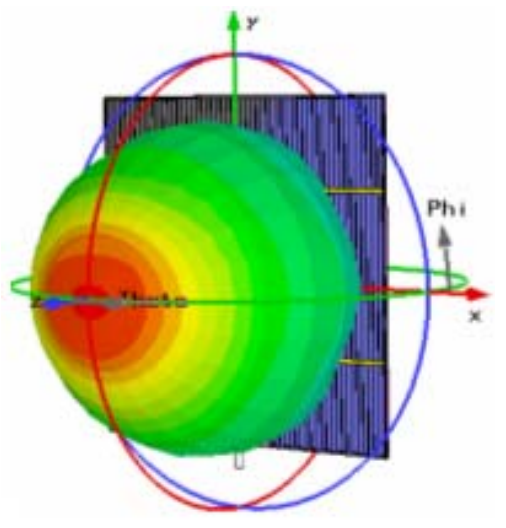

(a)

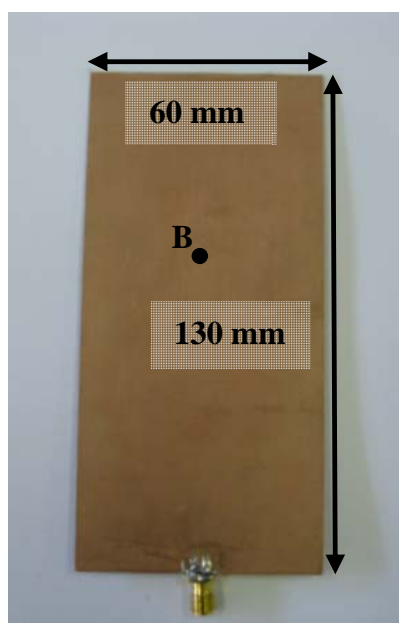

(b)

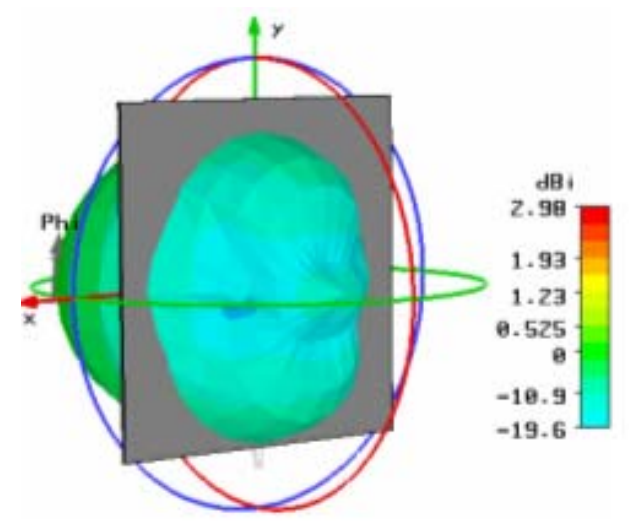

(b) 
Fig. 5.

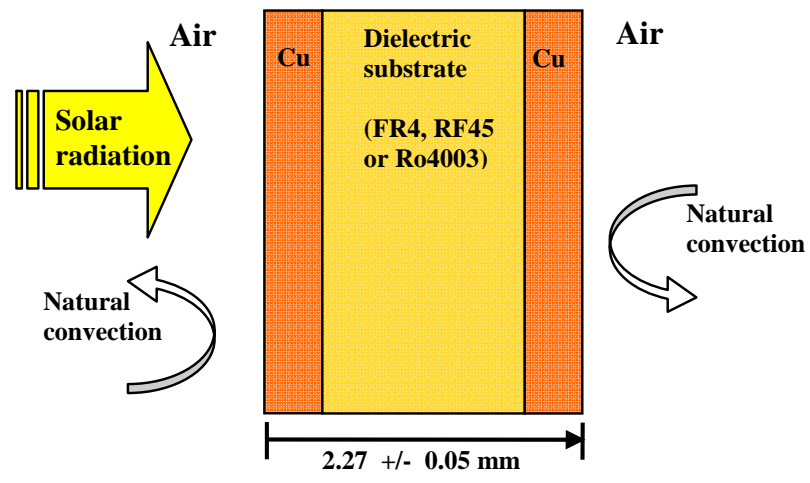

(a)

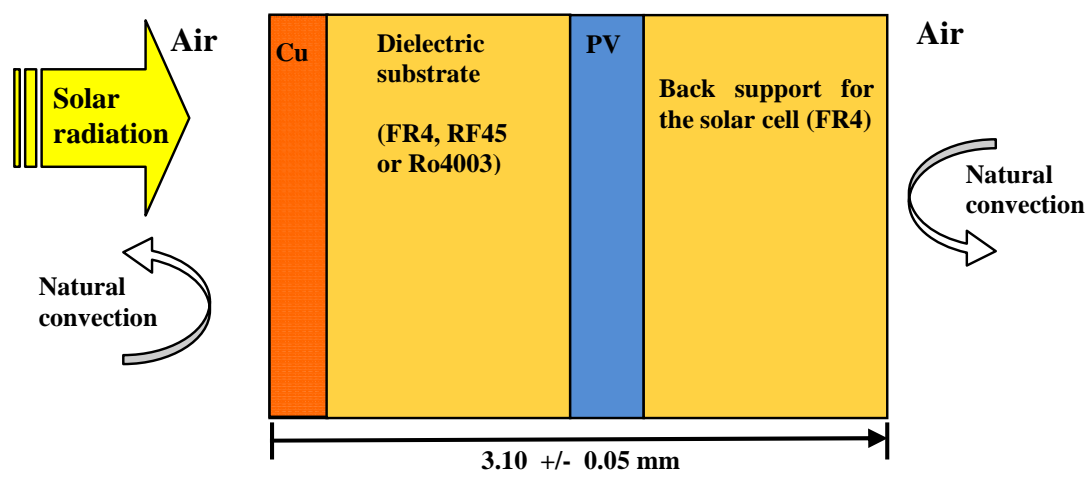

(b) 
Fig. 6.

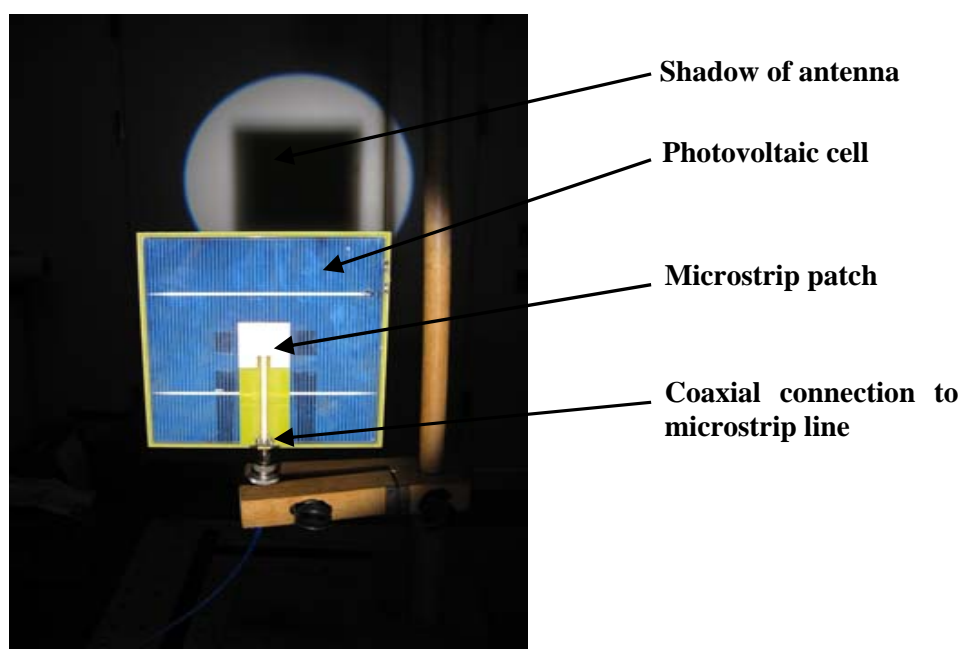


Fig. 7.
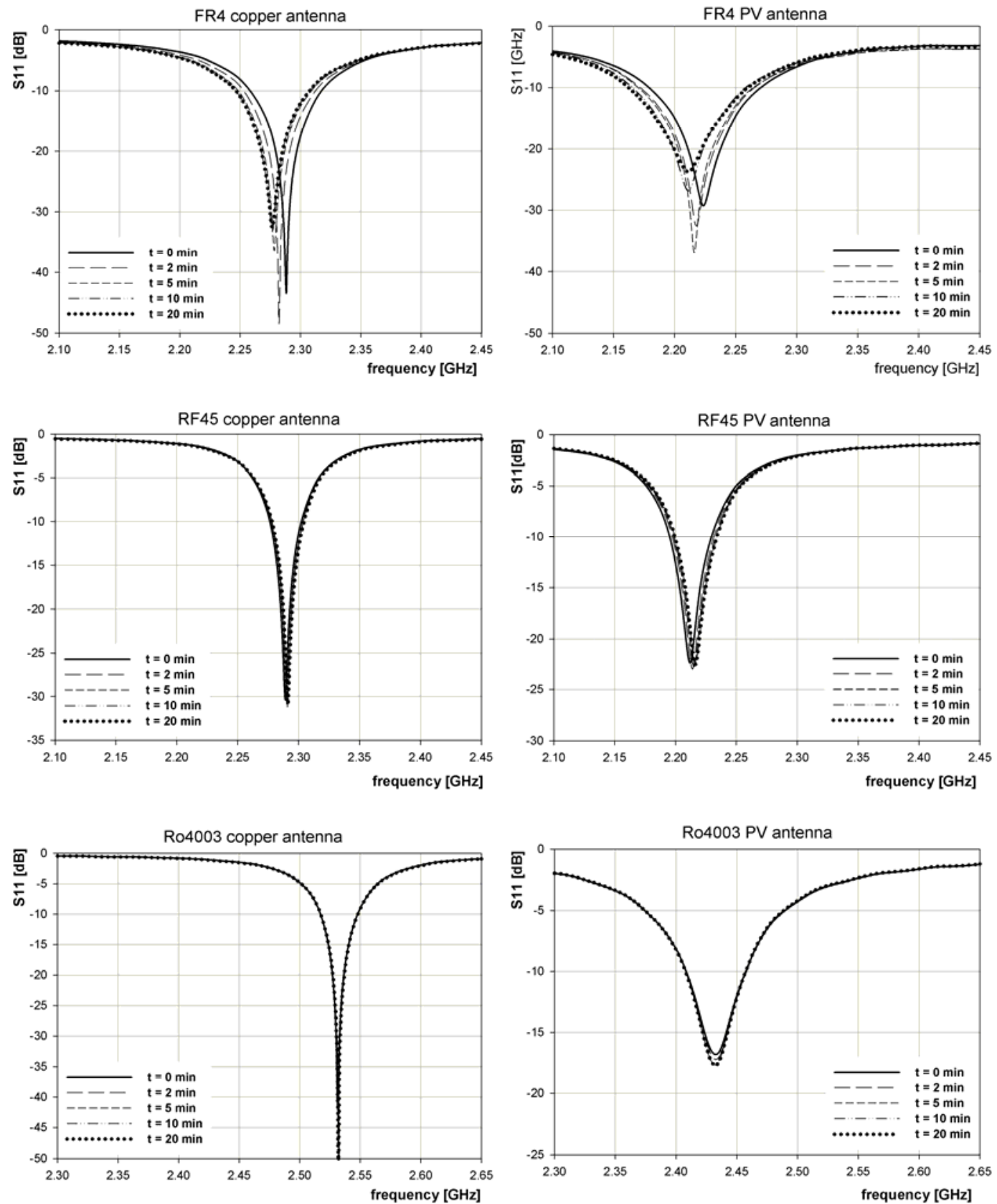
Fig. 8.
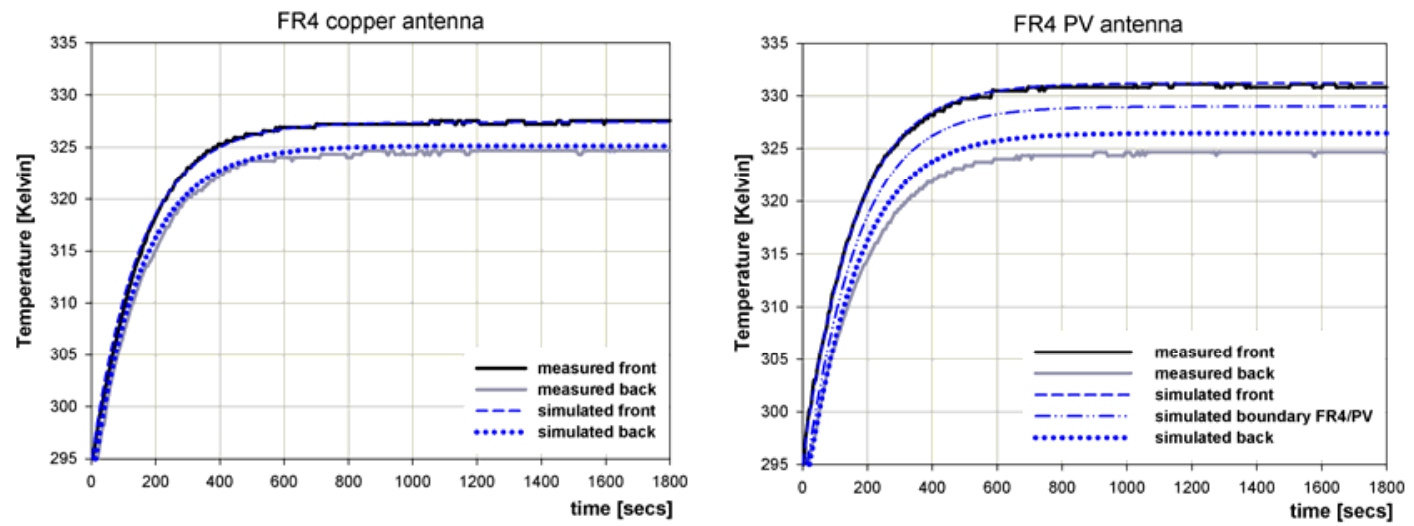

(a)

(b) 